\title{
Los servicios sociales frente a la exclusión.
}

\author{
Manuel Aguilar Hendrickson \\ Universitat de Barcelona \\ <manuel.aguilar.hendrickson@ub.edu>
}

Marta Llobet Estany

Universitat de Barcelona

\section{Begoña Pérez Eransus}

Universidad Pública de Navarra
Gainkarga gertatzen ari dira gizarte-zerbitzuen alorrean krisialdiak sortarazi dituen ekonomiamailako herritarren zailtasunak. Arazo horietako batzuek orain horren larriki azaldu arren, krisialdiaren aurreko arazoen ondorio dira. Arazo horiek zerikusia dute Espainian nahi izandako Estatu sozial modernoaren gizarte-zerbitzuak ezartzean gertatutako hutsegitearekin, eta geldiaraztearen erantzule da, baita ere, ongintzan indartutako eredua eta laguntza jasotzeko sarbide izateko arautu gabeko babes ekonomikoaren kudeaketa. Egoera hobetzearren aurkezten dira zenbait proposamen, adibidez, gizarte-zerbitzuen eta laguntza sozialaren funtzio propioak bereizten, edo gertutasuneko laguntzearen aldeko espazioa eta ekintza komunitarioa indartuz.

\section{HITZ-GAKOAK:}

gizarte-zerbitzuak, bazterketa, gizarteratzea, pobrezia, laguntzea.
Las dificultades económicas de muchas personas ocasionadas por la crisis están suponiendo una sobrecarga para los servicios sociales. Parte de los problemas que se presentan de forma especialmente aguda en estos momentos, sin embargo, derivan de problemas anteriores a la crisis. Dichos problemas tienen que ver con el encaje insatisfactorio de los modernos servicios sociales en el Estado social en España, con el peso del modelo tutelar de la beneficencia y con el colapso del espacio de la incorporación y el acompañamiento bajo el peso de la gestión de una protección económica discrecional. Se proponen vías de salida de la situación, como la diferenciación de las funciones propias de los servicios sociales de las de asistencia social, y la apertura de espacios para el acompañamiento desde la proximidad y la acción comunitaria.

\section{PALABRAS ClaVe:}

servicios sociales, exclusión, incorporación social, pobreza, acompañamiento. 


\section{Crisis: pobreza, exclusión social y servicios sociales}

Una parte significativa de la población española está sufriendo dificultades económicas graves como consecuencia de la fuerte destrucción de empleo de los últimos tres años. El número de hogares que, según la Encuesta de Población Activa, no tienen ningún perceptor de ingresos salariales, ni gozan de la protección social general (pensiones ni prestaciones por desempleo) pasó de 333.000 a fines de 2005 a 461.000 a finales de 2009, y alcanza los 584.000 a principios de 2012. En número de personas, el salto fue de 620.000 en 2005 a 962.000 en 2009 , y a 1,24 millones a principios de 2012.

Gráfico 1. Hogares con todos sus miembros activos parados y hogares sin ingresos. España, 2005-2012

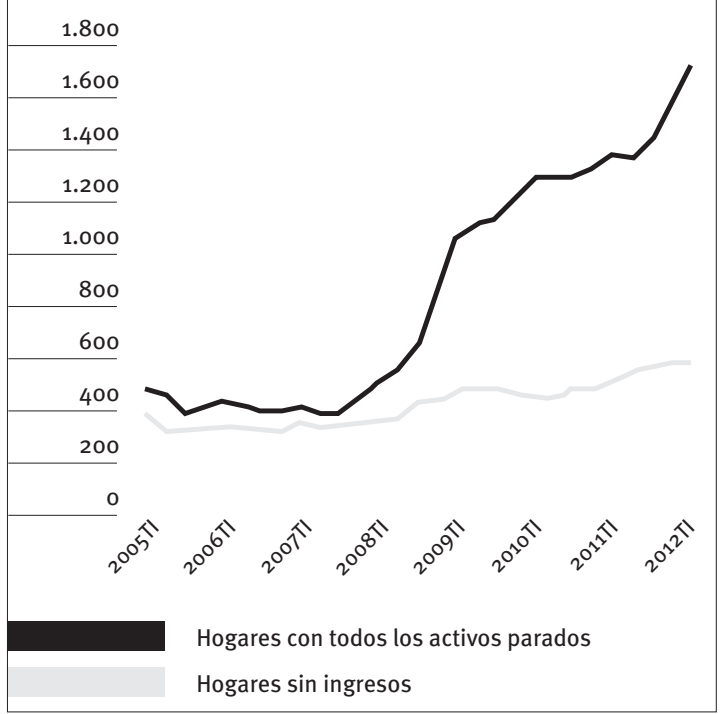

Fuente: Encuesta de Población Activa.

Estas cifras son un indicador claro de la tendencia, pero no es el único. El número de hogares con todos sus activos en paro ha crecido a un ritmo aún mayor, acercándose a 1,8 millones a principios de 2012. Muchos de estos hogares perciben alguna prestación por desempleo, en muchas ocasiones de cuantía bastante reducida, lo que los coloca en una situación de dificultad económica extrema. Además, la destrucción de empleo de estos últimos años se ha producido en un contexto de elevados costes de la vivienda y de un importante sobreendeudamiento de los hogares, que añade a las dificultades de quienes carecen de ingresos las de quienes manteniendo algunos ingresos (uno de los dos salarios, prestaciones por desempleo) se ven en la imposibilidad de hacer frente a los gastos de mantenimiento mensuales.

El empeoramiento de la situación económica de numerosos hogares ha tenido un efecto apreciable en los servicios sociales, en especial en los de atención primaria. Aún no disponemos de estadísticas generales que permitan medirlo en términos de incremento de la demanda, pero hay datos procedentes de fuentes diversas (noticias en los medios, declaraciones de responsables institucionales) que indican que dicho incremento ha sido importante. Las consejerías responsables de servicios sociales de diversas comunidades han anunciado que el número de solicitudes de prestaciones de renta mínima y de ayudas de emergencia social (que, en la gran mayoría de los casos, se tramitan a través de los servicios sociales locales) se ha incrementado de forma notable durante los dos últimos años. Por su parte, Cáritas Española ha informado de un incremento continuo del número de personas atendidas en sus servicios de acogida y atención primaria, que se duplicó entre 2007 y 2009, pasando de 370.000 a casi 790.000 (Cáritas Española, 2010).

Este incremento de la demanda se ha producido en un momento en el que los servicios sociales de atención primaria de muchas comunidades autónomas estaban absorbiendo la demanda suscitada por la implantación del Sistema de Autonomía y Atención a la Dependencia (SAAD), demanda no sólo importante en términos cuantitativos, sino también exigente en términos de cambios en los modos de actuación. Ha llegado tras una etapa relativamente larga de crecimiento del empleo, que había dejado atrás las tensiones de un largo periodo de alto desempleo en los años ochenta y primeros noventa. El anterior crecimiento del empleo había permitido, en algunos territorios, empezar a abordar con mayor tranquilidad procesos de acompañamiento de la inserción social y sociolaboral de personas en dificultad social.

Cuando se habla con responsables y trabajadores de los servicios sociales locales, se percibe un malestar que no parece explicable sólo por el exceso de carga trabajo que supone esta situación. Son frecuentes las opiniones acerca de la imposibilidad de dar respuesta adecuada a las situaciones que se presentan, y hay datos que parecen confirmar dicha percepción. Este malestar se expresa con frecuencia poniendo en duda que los servicios sociales deban gestionar las rentas mínimas, o aludiendo a la aparición de demandantes de renta mínima 'no excluidos', para los que no se dispone de una oferta adecuada y que, con frecuencia, tampoco se sienten muy cómodos en los servicios sociales. También es síntoma de dicha inadecuación el hecho de que una mayoría de las personas atendidas por Cáritas en 2009 (cerca de seis de cada diez) habían acudido con anterioridad a los servicios sociales públicos. La incapacidad para ofrecer una respuesta suficiente parece el motivo principal, y es frecuente que los propios servicios sociales públicos envíen a las personas atendidas a Cáritas.

\subsection{Los servicios sociales, (atrapados) entre la pobreza y la exclusión}

Un elemento característico del desarrollo moderno de los servicios sociales desde los años setenta y ochenta ha sido intentar escapar de su concepción de 'servicios para los pobres'. La beneficencia pública y su sucesora modernizada, la asistencia social, se 
definían por la población de la que se ocupaban (los pobres, o las personas de ingresos bajos), y no por el tipo de acción que realizaban (educativa, de alojamiento y manutención, de apoyo personal, sanitaria). Los servicios sociales modernos quieren ser 'otra cosa' diferente (aunque, como veremos más adelante, esa 'otra cosa' no acaba de estar bien definida), pero heredan en parte el espacio de la beneficencia y la asistencia social en el espacio institucional, en el 'mandato' que reciben y en el imaginario de los ciudadanos. Nuestra hipótesis es que el problema debería abordarse definiendo la especificidad de los servicios sociales en relación con los demás sistemas de política social, más que intentando borrar de su imaginario a pobres, marginales y excluidos.

Esta inquietud se ha traducido en una afirmación doble de los servicios como 'universales' y prioritariamente 'generalistas'. La universalidad afirmada no ha tenido en muchas ocasiones efectos reales, ya que, al disponer de pocos medios, se ha acabado por dar prioridad de acceso a las personas de renta baja, opción legítima, pero contraria a la universalidad. La prioridad de lo generalista, de lo inespecífico, en especial en el nivel local o primario, derivaba tanto de corrientes favorables a lo generalista procedentes del Reino Unido y de Estados Unidos (aunque en contextos y con significados muy diferentes), como de la preocupación por evitar la pervivencia de la imagen de servicios encargados de atender a los pobres y marginados.

Un elemento central de los nuevos servicios sociales ha sido el desarrollo de servicios locales, de carácter generalista ${ }^{2}$. En los últimos decenios, se ha producido un progresivo desarrollo de una red que ha llegado a casi todo el territorio. Esta red se ha ido extendiendo, proporcionando un acceso universal (o muy amplio) a servicios de información y orientación a la ciudadanía, así como el acceso (más limitado y no siempre bien orientado) a algunos programas específicos de atención a domicilio, prestaciones de mínimos o recursos de alojamiento.

Sin embargo, atender estas actividades de información y orientación ha condicionado la intervención diaria de estos servicios, que se ha centrado, sobre todo, en responder a las demandas planteadas. La gestión de la información y la tramitación de las prestaciones concentran la mayor parte del esfuerzo profesional, lo que deja escaso espacio para diseñar acciones de atención específica, o procesos de intervención profesional de mayor profundidad y continuados en el tiempo.

Por ello la acción en materia de incorporación social con colectivos excluidos ha quedado, en muchos casos, reducida a favorecer su acceso a las prestaciones de garantía de ingresos (rentas mínimas y otros) y su orientación o derivación hacia recursos de for-

${ }^{2}$ La denominación de tales servicios es múltiple: servicios sociales de base, unidades de base, atención social primaria, servicios sociales generales o comunitarios, entre otras. mación, empleo o incorporación social gestionados, en su mayoría, por entidades sociales. Los procesos de intervención intensos con población excluida impulsados directamente desde la red de servicios sociales de atención primaria son limitados.

A partir de la Encuesta de Condiciones de Vida de la Población Española, especialmente realizada para elaborar el VI Informe FOESSA (Renes, 2008), hemos podido aproximarnos a la relación entre acceso a los servicios sociales y grado de integración social. De acuerdo con esta encuesta, el colectivo más numeroso dentro de la población usuaria es el de aquellos hogares que se encuentran en situación de integración precaria, que suponen casi la mitad de la demanda. Se entiende por 'integración precaria' la vulnerabilidad causada por determinados factores de índole sobre todo económica (déficit de acceso al empleo o a los sistemas de protección social), pero en situaciones en las que existen vínculos de integración relacionados con las redes familiares o sociales, y la propiedad de la vivienda.

Tabla 1. Personas que han acudido alguna vez a los servicios sociales. España, 2007 (\%)

\begin{tabular}{|l|c|}
\cline { 2 - 2 } \multicolumn{1}{c|}{} & $\%$ \\
\hline Integrado & 29,9 \\
\hline Integración precaria & 44,8 \\
\hline Exclusión compensada & 16,2 \\
\hline Exclusión severa & 9,0 \\
\hline Total & $\mathbf{1 0 0 , 0}$ \\
\hline
\end{tabular}

Fuente: Encuesta FOESSA (2007).

El segundo grupo más numeroso de personas que hacen uso de la red es el que se encuentra en situaciones de 'integración'. Sin embargo, las personas con problemas de exclusión no llegan a la cuarta parte de la población atendida por los servicios sociales. Las situaciones de exclusión más grave o severa (que acumulan problemas en diversos ámbitos) no llegan al $9 \%$ de los usuarios. Este dato nos indica cuánto suponen los excluidos sobre el conjunto de usuarios. Sin embargo, el dato que verdaderamente alerta sobre la limitada utilización de los servicios por parte de la población más excluida es la proporción de ésta que llega a los servicios sociales: tres cuartas partes de la población en situación de exclusión no tienen contacto con los servicios sociales.

Tabla 2. Personas que han acudido alguna vez a los servicios sociales, por grupos. España, 2007 (\%)

\begin{tabular}{|l|c|c|c|c|c|}
\cline { 2 - 6 } \multicolumn{1}{c|}{} & Integrado & $\begin{array}{c}\text { Integración } \\
\text { precaria }\end{array}$ & $\begin{array}{c}\text { Exclusión } \\
\text { compensada }\end{array}$ & $\begin{array}{c}\text { Exclusión } \\
\text { severa }\end{array}$ & Total \\
\hline Sí & 9,3 & 18,7 & $\mathbf{2 0 , 1}$ & 25,3 & $\mathbf{1 4 , 8}$ \\
\hline No & 90,7 & 81,3 & 79,9 & 74,7 & $\mathbf{8 5 , 2}$ \\
\hline Total & $\mathbf{1 0 0 , 0}$ & $\mathbf{1 0 0 , 0}$ & $\mathbf{1 0 0 , 0}$ & $\mathbf{1 0 0 , 0}$ & $\mathbf{1 0 0 , 0}$ \\
\hline
\end{tabular}

Fuente: Encuesta FOESSA (2007). 
Es difícil identificar las barreras que dificultan el acceso de la población excluida a los servicios sociales. Cuando se pregunta a la población en situación de exclusión severa los motivos por los cuales nunca ha tenido contacto con el sistema de servicios sociales públicos, casi dos tercios $(63,2 \%)$ dicen no conocerlos, proporción que duplica a la del colectivo de personas que se encuentra en situación de exclusión compensada (33\%). En este grupo, precisamente, el acceso a los servicios sociales y sus prestaciones, junto con la existencia de redes sociales de apoyo, pueden ser uno de los factores claros de compensación de esas situaciones. Las amistades, los contactos y la capacidad para resolver trámites constituyen factores de integración que favorecen el acceso a los servicios y cuya ausencia caracteriza las situaciones de exclusión más severa.

Un segundo grupo de factores lo integran aquellos relacionados con la capacidad de captación del propio sistema respecto a la población excluida. La limitada capacidad de detección más allá de las demandas planteadas, la rigidez de las formas de acceso (atención en horario de oficina, cita previa) y las escasas respuestas efectivas para las situaciones de exclusión pueden influir en que las personas excluidas no recurran a dichos servicios.

También resulta significativo que el grado de satisfacción respecto al sistema de servicios sociales está estrechamente relacionado con el nivel de exclusión social de la población. Las personas en situación de exclusión severa son las más insatisfechas con los servicios sociales. Casi dos tercios (más del 63\%) se muestran poco o nada satisfechas con el sistema, mientras que el grado de satisfacción en el resto de colectivos es mucho más elevado. Las causas, a juicio de los encuestados, de este grado de insatisfacción de los más excluidos son la lentitud y burocracia a la hora de resolver los trámites, la falta de respuestas adecuadas a su situación, la falta de información y las listas de espera.

Tabla 3. Grado de satisfacción con los servicios sociales. España, 2007 (\%)

\begin{tabular}{|l|c|c|c|c|c|}
\cline { 2 - 6 } \multicolumn{1}{l|}{} & Integrado & $\begin{array}{c}\text { Integración } \\
\text { precaria }\end{array}$ & $\begin{array}{c}\text { Exclusión } \\
\text { compensada }\end{array}$ & $\begin{array}{c}\text { Exclusión } \\
\text { severa }\end{array}$ & Total \\
\hline $\begin{array}{l}\text { Muy } \\
\text { satisfecho }\end{array}$ & 36,6 & 15,9 & 32,6 & 8,5 & $\mathbf{2 3 , 6}$ \\
\hline $\begin{array}{l}\text { Bastante } \\
\text { satisfecho }\end{array}$ & 40,5 & 45,3 & 32,6 & 29,8 & $\mathbf{4 0 , 3}$ \\
\hline $\begin{array}{l}\text { Poco } \\
\text { satisfecho }\end{array}$ & 19,8 & 27,6 & 23,3 & 44,7 & $\mathbf{2 6 , 4}$ \\
\hline $\begin{array}{l}\text { Nada } \\
\text { satisfecho }\end{array}$ & 3,1 & 11,2 & 11,6 & 17,0 & $\mathbf{9 , 7}$ \\
\hline Total & $\mathbf{1 0 0 , 0}$ & $\mathbf{1 0 0 , 0}$ & $\mathbf{1 0 0 , 0}$ & $\mathbf{1 0 0 , 0}$ & $\mathbf{1 0 0 , 0}$ \\
\hline
\end{tabular}

Fuente: Encuesta FOESSA (2007).
Sería injusto no reconocer aquí la importancia que han tenido los servicios sociales de atención primaria en favorecer el acceso de (una parte de) los sectores excluidos a las rentas mínimas y otros recursos, así como la labor de seguimiento que han desarrollado aprovechando el contexto de tramitación y adjudicación de las prestaciones. Sin embargo, desde el propio sector se reconocen las limitaciones de recursos humanos y materiales para llevar a cabo procesos de incorporación social más intensos.

La percepción de responsables y profesionales a los que hemos entrevistado es que, a lo largo del tiempo y coincidiendo con la expansión de los servicios sociales, el conjunto de la población ha tenido un mayor conocimiento de su existencia y se ha producido un mayor acceso de personas 'integradas' vinculadas a la demanda de información y acceso a los servicios, en especial en relación con las personas mayores y con discapacidad. La sobrecarga de tareas de información y gestión de prestaciones se muestra como una de las principales barreras para desarrollar trabajo social de incorporación con colectivos excluidos. Algunos vislumbran en los años más recientes un incremento de esta tendencia de desplazamiento de los más excluidos, debido a la asunción de la responsabilidad de gestión del SAAD.

Los síntomas que hemos descrito hasta aquí hacen pensar que el problema es algo más profundo que el derivado de un incremento puntual de la demanda. Es evidente que cualquier sistema de servicios que experimente un crecimiento en un breve periodo de tiempo de su demanda se ve sometido a tensiones, como sucede en estos mismos años con el aumento de las solicitudes de admisión en las universidades y los centros de formación profesional, como consecuencia de la crisis de empleo, o como sucedió con la renovada demanda de plazas escolares en los años noventa, cuando el sistema educativo empezaba a hacerse a la idea de que no volvería a tener muchos alumnos. Sin embargo, en el caso que nos ocupa, el grado de tensión y de dificultad para responder a la situación es mucho mayor y remite, en nuestra opinión, a problemas más de fondo.

Los problemas derivados de la implantación del SAAD tenían que ver, sobre todo, con el volumen de población que había de atender (y la oferta de servicios necesaria para hacerlo) y con la introducción de una lógica de derecho subjetivo en un sistema acostumbrado a racionar la atención de forma discrecional. Pero nadie pone en duda que atender a las personas que han perdido autonomía mediante residencias, centros de día, atención a domicilio y otros servicios similares era tarea propia de los servicios sociales. Era algo que venían haciendo, y que debían seguir haciendo, adecuándose al nuevo marco.

En el caso de la pobreza derivada de la crisis del empleo, sin embargo, la cuestión no está tan clara. ¿Es responsabilidad de los servicios sociales asegurar que las personas que han perdido sus ingresos 
del trabajo puedan hacer frente a sus necesidades de subsistencia? En principio, parece que tal responsabilidad corresponde, en nuestro sistema de protección social, al ámbito de la garantía de rentas, y de forma más precisa, a la protección por desempleo. Ni las leyes generales ni las de servicios sociales atribuyen una función de garantía de renta a los servicios sociales. A pesar de ello, los servicios sociales han intervenido en este terreno desde hace años, por medio de ayudas económicas puntuales y discrecionales y, en algunas comunidades y desde principios de los años noventa, por medio de las rentas mínimas de inserción.

\section{2. ¿Para qué sirven los servicios sociales?}

A nuestro entender, una parte del problema deriva de un encaje insatisfactorio de los servicios sociales en el Estado de bienestar español (Aguilar Hendrickson, 2009). En nuestro país, se superponen dos concepciones de la acción social pública incoherentes entre sí:

- Por una parte, la concepción que heredamos del régimen de la asistencia liberal (fundado en la beneficencia pública) y que intentó modernizarse en los años sesenta y setenta en forma de asistencia social. Esta concepción preveía un dispositivo de atención global a la pobreza (en varios ámbitos, como el económico, el sanitario o el educativo), separado de la protección social del grueso de la población trabajadora (previsión social o Seguridad Social). Es decir, preveía la existencia de un dispositivo institucional encargado de ‘hacerse cargo' de los pobres. Su consistencia proviene de tener como objeto el conjunto de las necesidades de una parte de la población.

- La otra concepción distingue entre dispositivos institucionales encargados de atender diferentes partes de las necesidades de la población. Este modelo de Estado de bienestar se articula en torno a sectores de la acción social pública (sanidad, educación, garantía de rentas), y no de grupos de población. Su coherencia técnica, condición de su eficacia y eficiencia, deriva de atender una parte definida de las necesidades del conjunto de la población.

La posición contradictoria de los servicios sociales entre estos dos modelos es comprobable en la percepción de la opinión pública y de los propios ciudadanos que los usan (que los siguen identificando con la 'beneficencia' o la 'asistencia social'), en las ambigüedades de su encaje institucional (los servicios sociales como plasmación de la competencia autonómica en 'asistencia social') y en la propia acción de los servicios. Pensamos que clarificar el papel de los servicios sociales, en especial respecto a la exclusión, es condición imprescindible para salir del embrollo y las tensiones en las que están inmersos y para desarrollar una acción eficaz contra la exclusión.
Este encaje contradictorio se presenta de dos modos: en la pervivencia de concepciones y estructuras procedentes de la antigua beneficencia pública en los servicios sociales modernos; y en una delimitación insatisfactoria de las funciones propias, específicas de los servicios sociales como sector en el nuevo modelo.

\subsection{La pervivencia del modelo de la beneficencia pública}

La beneficencia pública fue, al menos como proyecto, el núcleo de un modo de acción social del Estado que Mariano Esteban de Vega (1992) ha denominado 'asistencia liberal'. La beneficencia pública intentó poner en marcha una regulación pública y una racionalización de la asistencia a los pobres incapaces de trabajar, y modificó sustancialmente su estructura financiera. Como proyecto, contó con fundamentos teóricos y con una articulación programática relativamente sólida, aunque su desarrollo fuese muy contradictorio y limitado (Carasa Soto, 2007). El modelo residual de política social liberal, lastrado por elementos arcaicos y nunca plenamente desarrollado (Carasa Soto, 2004), ciertamente mostró su incapacidad para hacer frente con eficacia a la cuestión social, a las nuevas formas de pobreza y de desigualdad nacidas del desarrollo económico, y ello ha llevado a leer su historia como la de un fracaso, lentamente superado por el progresivo desarrollo de la previsión social.

La beneficencia pública, sin embargo, sobrevivió al nacimiento y desarrollo de la previsión social, y siguió caracterizando un sector proporcionalmente cada vez menor de la acción social del Estado, hasta desaparecer entre la Constitución de 1978 y la Ley de Fundaciones de 1992. Suele verse como una reliquia fósil del pasado, cargada de connotaciones negativas, muchas de ellas probablemente justificadas. La beneficencia pública fue vista por buena parte de las clases trabajadoras como una respuesta inadecuada, insuficiente y teñida de paternalismo moralista y autoritario a sus dificultades, lo que explica el fuerte rechazo que despertaba en la cultura política del movimiento obrero y de la izquierda.

Paralelamente, los intentos de modernizar la atención social y resituarla en el contexto del naciente Estado social español en la década de 1960 cargaron en ocasiones las tintas sobre el arcaísmo de muchos de sus dispositivos, y sobre su carácter supuestamente graciable y voluntario. Tanto el proyecto de la 'asistencia social' (complemento de la Seguridad Social) de los años sesenta, como el de los 'servicios sociales' (nuevo sector con vocación universalista de la política social) de los setenta y ochenta, se definieron en términos de rechazo y superación de la beneficencia pública, y por ello cargaron las tintas en la crítica. Algunos autores trataron de matizar algunas de esas críticas (Aznar López, 1990, 1996; Casado, 2002), sin que ello cambiase sustancialmente el discurso dominante. 
El modelo de acción social pública sobre la pobreza de la beneficencia pública presentaba algunas características que es importante tener en consideración ${ }^{3}$ :

- La concepción de fondo era la de establecer un dispositivo de atención integral (social, sanitaria, educativa, laboral) para un sector de la población, el definido como pobre no culpable. Esta concepción incluye los dos aspectos, el de la 'selectividad' y el de la 'integralidad'. La opción por la selectividad (atender sólo a los pobres) es coherente con la concepción liberal de la atención pública sólo para los excluidos del mercado (el modelo 'residual' en los términos de Richard Titmuss). La opción por la integralidad, es decir, por una atención (en establecimientos o domiciliaria) que no establecía barreras absolutas entre el cuidado personal, la atención sanitaria, la educación y el trabajo, es otro rasgo del modelo, consecuencia de una baja especialización técnica de cada una de esas funciones. Cierto es que, a lo largo del desarrollo de la beneficencia pública, se fueron separando parcialmente algunas de ellas. La beneficencia sanitaria y social ('hospitalidad' y 'socorros') ya aparecían parcialmente deslindadas desde las primeras leyes de beneficencia, y desde principios del siglo XX se fue produciendo una separación de la beneficencia educativa. En todo caso, la concepción de fondo es la de hacerse cargo del conjunto de las necesidades de una parte de la población.

- Una regulación del acceso caracterizada por el establecimiento de obligaciones del Estado sin reconocimiento de derechos a los ciudadanos. De ese modo, la beneficencia pública se diferenciaba de la acción graciable o voluntaria (que, por definición, no está obligada a nada) y también de la acción que los ciudadanos que reúnen ciertas características pueden exigir de la Administración (los derechos). Lo que está en juego aquí no es la 'generosidad' o no en la provisión de apoyos. Lo que está en juego es la posición en la que quedan los ciudadanos respecto a la Administración. La persona socorrida queda en una posición equivalente a la minoría de edad: "Este doble infortunio constituye al hombre en un estado de minoría a que corresponde una solícita tutela en el gobierno cuyos paternales cuidados le revisten con el carácter de segunda providencia para el desvalido" (Colmeiro, 1850: 426). La persona, por tanto, puede exponer su situación y debe esperar que sea la Administración la que decida si su caso merece ser protegido o no. La obligación de la Administración, en este modelo, es la de proteger una serie de bienes (la 'función estatal' de la que habla Vida Soria [1968]), como el orden social, la salud pública y la vida de los miembros de la sociedad. El interés de las personas no está legitimado, salvo si satisfacerlo sirve a la función estatal, y la autonomía de las personas queda

3 Un análisis más detallado de esta cuestión puede hallarse en Aguilar Hendrickson (2010). muy limitada, al colocarse en una posición de 'menor tutelado'.

- La fragmentación de la responsabilidad pública entre tres niveles territoriales (central, provincial y municipal). La Ley de Beneficencia de 1849 cambió la responsabilidad exclusiva municipal (nunca implantada de hecho) por un reparto complicado entre los tres niveles, que conllevó, en la práctica, la concurrencia en un mismo territorio de diferentes acciones públicas, en ocasiones contradictorias. El nivel central se reservó funciones directas muy limitadas (establecimientos muy especializados, en principio) y la responsabilidad de la supervisión ('protectorado') de las entidades privadas (beneficencia particular). Los niveles provincial (sobre todo) y municipal cargaron con el peso de la acción pública, que se fue definiendo cada vez más en términos de obligación de disponer de determinado tipo de establecimientos, más que de garantizar la atención de determinadas situaciones.

Algunos elementos clave de estas tres características han pervivido tras la supresión de la beneficencia pública y el establecimiento de los servicios sociales modernos. La fragmentación de la responsabilidad pública sigue siendo una característica de los servicios sociales (a diferencia de la educación, la sanidad o las pensiones), ligeramente más compleja con la aparición del nivel autonómico, que, en parte, sustituye y, en parte, se añade al provincial. El escaso reconocimiento de derechos subjetivos a los ciudadanos en relación con los servicios sociales (al menos hasta la Ley de Dependencia y las últimas leyes de servicios sociales) ha mantenido un modelo de relación de tutela con los ciudadanos en términos de 'dígame usted qué le pasa y yo decidiré lo que le ofrezco'.

A pesar de fundarse en una obligación genérica de atención a los pobres, el desarrollo de la beneficencia publica en España combinó la creación obligatoria de determinados establecimientos por parte, sobre todo, de las diputaciones provinciales, con el desarrollo de numerosas actividades voluntarias (tanto públicas como de la llamada 'beneficencia particular'). Este carácter voluntario de buena parte de las acciones, junto a la multiplicidad de actores institucionales públicos, nos ha legado un sector público que, en ocasiones, se comporta aún hoy como un amplio y diverso sector voluntario de titularidad pública.

Finalmente, el paso de una concepción de atender todas las necesidades de 'una parte de la población' a la de atender 'una parte de las necesidades' de la población (toda o parte, según se opte por un modelo universalista o no) se ha producido sólo a medias. A la insuficiencia de esta transformación han contribuido varios factores, entre ellos la inercia institucional y social, pero también las peculiaridades del diseño del Estado de bienestar español entre los años sesenta y ochenta, por un lado, y la imprecisa 
delimitación del papel de los servicios sociales en la producción legislativa y teórica de los años ochenta en adelante.

\subsection{La división en sectores del Estado de bienestar}

Los Estados de bienestar desarrollados se caracterizan, entre otras cosas, por la diferenciación de sectores en su seno. Aunque las necesidades y los problemas de las personas constituyen un todo en la experiencia de sus vidas, las instituciones del Estado de bienestar van estableciendo progresivamente segmentos de esas necesidades, cada uno de los cuales es atendido desde un sector de la política social. Esos sectores tienden a institucionalizarse de forma diferenciada: definen su objeto (la enfermedad/ salud; el riesgo de perder el salario; la necesidad de adquirir conocimientos, destrezas y competencias), establecen su modelo de atención (la atención médica, las pensiones y prestaciones económicas, la enseñanza) y suelen articularse por medio de determinadas profesiones (las sanitarias -médicos, enfermeros-, las docentes). Su institucionalización diferenciada suele traducirse en el establecimiento de departamentos separados en la administración pública. Dicha configuración puede variar a lo largo del tiempo, por medio de reformulaciones de su objeto (de la 'enfermedad' a la 'salud', por ejemplo), de cambios de su modelo de atención (de la prioridad del hospital a la de la atención primaria, por ejemplo) y de reconfiguraciones de su mapa profesional.

En nuestro país, se habla con frecuencia de tres sectores o pilares, al que últimamente se le habría añadido un cuarto. Se trataría de: 1) la garantía de ingresos (pensiones y protección por desempleo), 2) la educación y 3) la sanidad, a los que se habría añadido 4) la atención a la dependencia o los servicios sociales, según los gustos. Hay otros sectores claramente visibles en nuestro Estado de bienestar, como el acceso al empleo (los servicios de colocación y las políticas activas de empleo) y la vivienda (por escuálida, ineficiente e ineficaz que sea su acción). Si aceptamos la presencia de estos dos últimos, estaríamos ante seis sectores, tal como lo formulaban Kahn y Kamerman (1987) hace ya unos años.

No hay que olvidar que esta diferenciación de las políticas sociales es una construcción social, y en cuanto tal, puede reconfigurarse subdividiendo o integrando sectores. Hay también espacios en los que podrían aparecer otros nuevos (por ejemplo, la gestión del tiempo libre y los equipamientos culturales y de ocio). Del mismo modo, la acción en cada sector puede articularse constituyendo un sistema, o puede aparecer fragmentada. El sector de la salud en España está articulado mayoritariamente en un único sistema (universal, con un financiador público único), aunque convive con servicios de salud privados externos al sistema (no al sector). Sin embargo, esta configuración es relativamente reciente: hasta la reforma de 1986 y su puesta en práctica a lo largo de los años noventa, el sector de la salud estaba compuesto por varios sistemas independientes (la atención sanitaria de la Seguridad Social y la de beneficencia, entre otros).

En el caso español, a la dificultad que supone la progresiva delimitación de ámbitos sectoriales, se añaden algunas peculiaridades del modelo adoptado de Estado de bienestar (Aguilar Hendrickson, 2009). Ya desde mediados del siglo XIX, se inician procesos de diferenciación sectorial, que, a lo largo del siglo $X X$, van madurando. En el decenio de los sesenta, se produce un primer impulso de diseño de un Estado de bienestar moderno con una fuerte inspiración conservadora o bismarckiana (Guillén, 2010; Rodríguez Cabrero, 1989). En este diseño empiezan a aparecer de manera bastante diferenciada un sector educativo (que tiende a orientarse hacia un modelo universalista, aunque internamente dualizado), y otros dos sectores (garantía de rentas y sanidad) construidos sobre un modelo contributivo. Hay algunos atisbos, que irán tomando cuerpo en los sesenta y setenta, de un 'cuarto' sector de servicios sociales (servicios para pensionistas y para minusválidos, sobre todo). Estos dos sectores 'y medio' (garantía de rentas, sanidad y los embrionarios servicios sociales) se configuran con un fuerte peso de los dispositivos contributivos, bajo el nombre de Seguridad Social. Pero al mismo tiempo, se hace evidente la necesidad de un segundo nivel de 'repesca' en los mismos sectores que proteja a la población de bajos ingresos que no ha cotizado (o no lo suficiente). Aunque este nivel no se desarrollase de forma plena, su denominación habitual era 'asistencia social' (o nivel asistencial), y parecía evidente que el punto de partida de su constitución debía ser un proceso de racionalización, modernización y división sectorial de la beneficencia pública. En esta concepción, la beneficencia pública debía desglosarse en garantía de rentas, asistencia sanitaria y atención social de asistencia social, en paralelo a la garantía de rentas, la asistencia sanitaria y la atención social contributivas de la Seguridad Social. Este proceso se inició y desarrolló de forma parcial, y sirvió para asentar en el lenguaje jurídico y administrativo el concepto de asistencia social, entendida como la protección no contributiva, condicionada a la insuficiencia de medios, pero reconocida como derecho subjetivo, en diferentes sectores de atención, complementaria de la Seguridad Social. Venía a ocupar un espacio parecido al de la beneficencia pública, pero integrada en el conjunto de una protección social mucho más amplia, reconocida como derecho y con una estructura de especialización sectorial más compleja.

Es esta 'asistencia social' la que aparece en la Constitución de 1978 y la que sirvió de base legal para que las comunidades autónomas pusieran en marcha sus políticas de servicios sociales. Pero los servicios sociales en cuestión no se concibieron a sí mismos como un nivel asistencial, o no contributivo, de protección, sino como un sector autónomo. Para que esta concepción definiera la realidad de los servicios sociales, era necesario, entre otras cosas, definir la especificidad de ese sector. Parte de las dificultades 
de los servicios sociales vienen de una insuficiente claridad en este asunto.

Para establecer los servicios sociales como sector de la política social, encargado de una parte de las necesidades de la población, es crucial identificar de qué parte de las necesidades se encargan, y de qué parte se encargan otros sectores. Los servicios sociales modernos en España han venido definiendo legalmente esta cuestión de un modo poco claro. Son frecuentes en las leyes definiciones inespecíficas (servicios tendentes a lograr el bienestar social y la calidad de vida de los ciudadanos) que poco dicen sobre de qué parte específica de ese bienestar se ocupan los servicios sociales, a diferencia de lo que sucede con la sanidad, la educación o la garantía de rentas (de las que sí sabemos de qué parte se ocupan). También abunda la identificación de grupos y situaciones atendidas (mayores, menores, adultos, personas con discapacidad, mujeres, inmigrantes, personas con problemas de drogas, entre otros). Debería ser evidente que los servicios sociales no se ocupan de todas las necesidades de estos grupos (como lo hacía la beneficencia pública), pero en las leyes no queda nada claro de qué parte concreta de las necesidades de estas personas se ocupan.

Definir los límites del encargo que se hace a los servicios sociales supone decidir entre diversas alternativas posibles. No hay una definición absoluta de servicios sociales, como ni siquiera es necesario que sus funciones se integren en un sector único y diferenciado de la política social. Los servicios sociales podrían no existir como tales, y las funciones que parece lógico atribuirles podrían ser ejercidas desde otros sectores. Se trata de optar entre diversas posibilidades de configuración del sector, ninguna de las cuales se debe a una realidad ontológica de los servicios sociales.

¿Cuáles son esas funciones? Las principales tienen que ver con: a) el apoyo en lo cotidiano a las personas que han perdido autonomía; b) la tutela y protección de los menores (pero también de personas incapacitadas o vulnerables a tratos inadecuados); y c) el apoyo a las personas con dificultades especiales de integración social en sus procesos de incorporación. Estas funciones son diferentes (en sus finalidades y métodos de acción) de otras 'cercanas', como la garantía de ingresos, la atención sanitaria o las políticas de empleo. Es posible desarrollarlas desde un sector conjunto (los servicios sociales) o desde sectores ya existentes. El apoyo en la vida cotidiana a las personas con pérdida de autonomía es diferente de la atención sanitaria, pero podría desarrollarse desde los servicios de salud. La protección económica por desempleo forma parte de la política de garantía de ingresos y, en España, se ha optado por gestionarla desde los servicios públicos de empleo y no desde la administración general de la Seguridad Social (como en otros países). Más aún, es admisible que los servicios sociales gestionen las rentas mínimas de inserción, pero no por ello dejan de ser parte de la política de garantía de rentas. Las opciones en juego presentan ventajas e inconvenientes, y no pueden ser resueltas desde posiciones de principio.

La función que más nos interesa aquí es la tercera. Hace referencia al apoyo a los procesos de incorporación de personas que se encuentran con especiales dificultades para su integración social, por razones muy diversas, desde la discapacidad a la discriminación, desde la marginalidad a los problemas graves de salud.

\subsection{Especificidad y transversalidad en la acción contra la exclusión social}

Parece un contrasentido insistir aquí en la especificidad de la función de un sector, cuando se insiste al mismo tiempo en la necesidad de acciones transversales o integrales. El discurso político y técnico sobre la exclusión y la inclusión ha puesto énfasis en la multidimensionalidad de los problemas de exclusión social y en la necesidad de políticas integrales o transversales de inclusión. La multidimensionalidad de los problemas de inclusión hace referencia a la coincidencia en las personas en dificultad de diferentes problemas y dificultades que afectan al objeto de más de un sector de la política social (salud, educación, trabajo, dinero, vivienda). Además de coincidir, esos problemas parecen retroalimentarse, y su resolución parece difícil si no se abordan de manera integrada y conectada. Ello requiere de acciones desde los diferentes sectores de la política social, acciones adaptadas a las dificultades específicas de esas poblaciones.

El Estado de bienestar desarrollado, diferenciado en sectores, espera de los ciudadanos que sean capaces de gestionar esa fragmentación. Un ciudadano 'normal', integrado, debe ser capaz de saber para qué tiene que ir al centro de salud y para qué a la escuela; en definitiva, debe saber cómo gestionar la tensión entre la unidad de su situación personal y la diferenciación institucional. Sin embargo, muchas cosas hacen pensar que, en el caso de las personas en dificultad social grave (eso que llamamos 'exclusión'), es frecuente que la autogestión de las necesidades no funcione como debería. Por un lado, con frecuencia se trata de situaciones en las que las dificultades, los problemas y las necesidades en varios sectores no sólo coinciden, sino que se enlazan y se afectan recíprocamente, por lo que resulta especialmente difícil tratarlas por separado. Por otro, en muchos casos las personas en dificultad tienen límites importantes para gestionar esa complejidad o, mejor dicho, para gestionarla adaptándose a la diferenciación institucional de las políticas sociales.

En el marco de las políticas integrales o transversales de inclusión o contra la exclusión, es importante diferenciar dos planos. Por un lado, hay acciones que pueden incrementar la accesibilidad y la adaptación de cada sector de la política social para las personas en dificultad y reducir sus mecanismos exclusógenos. Por ejemplo, un sistema educativo más flexible 
y adaptado a diferentes tipos de estudiantes, que ofrezca múltiples mecanismos de repesca y de acceso a sus diferentes niveles resultará seguramente menos exclusógeno y más accesible que un sistema educativo rígido, orientado sólo hacia la carrera académica y universitaria, donde los fallos no se perdonan. En las páginas que siguen, y de modo completamente convencional, llamaremos políticas y acciones de inclusión a este tipo de políticas y acciones. No van dirigidas específicamente a las personas en dificultad, sino a incrementar la inclusividad de los diferentes sectores. Por otro lado, hay acciones que van directamente dirigidas a las personas en dificultad y tratan de construir procesos concretos de incorporación social. Su foco son las situaciones y procesos de las personas en dificultad, y tratan de articular acciones en diferentes sectores que les permitan desarrollar procesos personales que mejoren su situación. Llamaremos aquí políticas y acciones de incorporación a este tipo de acciones. Una acción eficaz contra la exclusión social requiere de ambos tipos de política. Las políticas sólo de incorporación corren el riesgo de tropezarse muy rápidamente con bloqueos y barreras excluyentes en los espacios e instituciones donde debería desarrollarse la incorporación. Las políticas sólo de inclusión pueden reducir el riesgo de exclusión y tener importantes efectos preventivos, pero al mismo tiempo pueden dejar fuera a los casos más graves y extremos de dificultad, que, por sí solos, es poco probable que puedan gestionar su incorporación.

Si se acepta esta diferenciación entre políticas de inclusión y de incorporación, la cuestión de la multidimensionalidad o transversalidad se plantea de forma diferente en cada una de ellas. En el caso de las políticas de inclusión, la integración de políticas es un problema de coordinación y cooperación interadministrativa. Se trata de articular mecanismos que aseguren que, en cada sector, se eliminan barreras excluyentes, se abren oportunidades para las personas con más dificultades, se adaptan mejor los servicios a poblaciones diversas. Sin embargo, en el caso de las políticas de incorporación, la transversalidad consiste en la gestión integrada de un proceso personal de desarrollo. No se trata de una mera coordinación interadministrativa (aunque su existencia facilita mucho las cosas), sino de articular, gestionar y acompañar un proceso personal (un itinerario, si se quiere) de incorporación.

\subsection{Un papel para los servicios sociales}

Una condición para la coordinación entre instituciones y la cooperación interprofesional es establecer con suficiente claridad la responsabilidad de cada una de las partes. En las líneas que siguen intentaremos establecer cuál es el papel que puede (debe) corresponder a los servicios sociales como sector específico en la acción contra la exclusión.

Aunque las administraciones empezaron a articular planes de lucha contra la pobreza, contra la exclusión o por la inclusión a lo largo de los años noventa (el País Vasco se adelantó con el Plan Vasco contra la Pobreza a finales de los ochenta), hay un antecedente de diseño legal de una política de integración social transversal o interdepartamental que data de principios de los años ochenta y aún está en vigor: la Ley de Integración Social de los Minusválidos (LISMI).

La LISMI articula una política de integración social, para lo que define su objeto (la minusvalía, hoy redenominada discapacidad) como la 'reducción de las oportunidades de integración' laboral, educativa o social derivada de una deficiencia física, psíquica o sensorial previsiblemente permanente. En este sentido, es claramente diferente de la Ley de Promoción de la Autonomía Personal y Atención a las Personas en Situación de Dependencia (LAPAD) -aunque algunas personas puedan hallarse en el ámbito de las dos leyes-, que no se define en relación con límites en las posibilidades de integración, sino con la necesidad de apoyos personales de terceros para desarrollar actividades básicas de la vida diaria, normalmente propias del ámbito doméstico. En este sentido, son leyes claramente diferentes en su objeto y su marco conceptual, aunque la inclusión de la figura del asistente personal en la LAPAD parece contradecir la claridad del modelo (esta figura ofrece más un apoyo a la integración social que una compensación de la dependencia).

La LISMI prevé acciones para promover la integración en diversos ámbitos. En el educativo, prevé que el sistema educativo establezca dispositivos para la incorporación a las escuelas ordinarias de las personas con discapacidad. En el del acceso al empleo, establece la reserva de puestos de trabajo en empresas ordinarias y la creación de empresas especiales adaptadas (los centros especiales de empleo). En la garantía de ingresos, creó un subsidio de garantía de ingresos mínimos específico, que, con el tiempo, se transformó en la pensión no contributiva por invalidez. No se trata aquí de presentarlas todas, pero éste es un ejemplo claro de articulación (mejor o peor desarrollada en la práctica) de una política multidimensional, transversal o integral para la integración social de un colectivo excluido.

La LISMI atribuye un papel específico a los servicios sociales, y señala algunas funciones que, aunque no atribuye a ningún sector en concreto, han acabado por corresponder a los servicios sociales. Los servicios sociales tendrían como responsabilidad central 'el desarrollo personal y la integración en la comunidad'. Ese 'desarrollo personal' tiene un sentido -si se consultan los documentos técnicos de la épocabastante similar a la idea de 'proceso de incorporación’ al que nos hemos referido antes. La integración en la comunidad hace referencia a la integración en espacios distintos del empleo, la educación o la salud, ya previstos en otros apartados de la ley. Se mencionan las acciones de integración en espacios sustitutivos del empleo para quienes no pueden trabajar (los centros ocupacionales), las acciones de apoyo en la vida diaria (atención domiciliaria, 
residencias), en el ocio, el deporte y el tiempo libre, la orientación a las personas con discapacidad y sus familias. La ley formula un concepto de los servicios sociales más claro y preciso que el de muchas de las leyes posteriores de los servicios sociales. Además, aunque no lo establecía la ley, se encargó posteriormente a los servicios sociales la función de valoración y calificación de la discapacidad.

Pensamos que este esquema nos da algunas pistas sobre cuál podría ser la definición del papel de los servicios sociales en las políticas de inclusión e incorporación. Seguidamente señalamos algunas de las tareas y funciones propias y específicas de los servicios sociales en este campo:

- La entrada en contacto y el establecimiento de vínculos con las personas en dificultad que permitan iniciar procesos de desarrollo personal para la incorporación social.

- La identificación, conjuntamente con las personas en dificultad, de las dificultades, limitaciones, capacidades y oportunidades para su desarrollo personal y su incorporación social. De esa identificación puede derivarse lo que se suele denominar valoración, es decir, algún tipo de reconocimiento formal de las dificultades y capacidades de la persona con efectos para su acceso a servicios o prestaciones.

- El acompañamiento de los procesos de incorporación, entendidos como procesos de desarrollo personal. Esto significa algo diferente y mucho más rico y complejo que el seguimiento, entendido como la verificación periódica de la situación. Este acompañamiento incluye facilitar el acceso y la incorporación a dispositivos de otros sectores (educativos, de salud, de acceso al empleo), cosa que no debe entenderse como simple orientación y derivación, sino también como mediación social del acceso y la incorporación.

- La provisión de apoyos orientados al desarrollo personal y a la integración en la comunidad, en el terreno de las capacidades personales y sociales, el funcionamiento familiar y doméstico, y las actividades de la vida diaria distintos del acceso a la educación formal, la atención sanitaria, o la formación y la inserción profesionales. Incluye acciones de tipo socioeducativo o psicosocial-como las habituales en programas de apoyo y educación familiar-, de mejora de habilidades sociales y personales, de potenciación de las capacidades y las redes sociales, o de impulso de la interacción y la participación sociales, entre otras.

Estas acciones pueden desarrollarse en un espacio no residencial, en el que la persona mantiene su vida cotidiana en el marco de su hogar, o en un espacio residencial, cuando por diferentes razones la persona no puede mantener su vida cotidiana en su hogar (porque carece de él, porque se encuentra en una situación de pérdida temporal de aquél, o porque lo especial de su situación así lo aconseja).
Señaladas las que nos parecen tareas propias de los servicios sociales, se pueden señalar algunas otras que no serían propias:

- La provisión de ingresos económicos de subsistencia a las personas que carecen de ellos. La garantía de ingresos mínimos (mediante una renta mínima -de inserción o no- o mediante otras prestaciones económicas) forma parte del sistema (y sector) de la garantía de rentas (pensiones, prestaciones por desempleo, salario mínimo), con cuyos otros componentes tiene que ser coherente (en cuantías, requisitos de acceso, paso de una prestación a otra). Su gestión puede hacerse desde los servicios sociales (como los servicios de empleo gestionan el acceso a las prestaciones por desempleo) si se considera que el acceso por esa vía facilita otro tipo de acciones de los servicios sociales (aunque cabe pensar que también puede dificultarlas). Tampoco sería descabellado que las rentas mínimas de inserción se gestionasen en los servicios de empleo, y que éstos pusieran a los perceptores que lo necesitaran en contacto con los servicios sociales (como ya está previsto en la regulación de la renta activa de inserción).

- La formación para el empleo y la inserción laboral tampoco son una tarea propia de los servicios sociales, como tampoco lo es el alojamiento permanente en una vivienda. Sin embargo, en los últimos años se han creado espacios para desarrollar las tareas que sí son propias de los servicios sociales (acompañamiento, apoyo al desarrollo personal) en el marco del empleo de inserción y el alojamiento tutelado.

La posición acerca de estas tareas impropias de los servicios sociales debería combinar la claridad conceptual y de responsabilidades con un cierto pragmatismo. El peligro es que su desarrollo en el marco de los servicios sociales distorsione las dos cosas. La gestión de las rentas mínimas desde los servicios sociales puede tener la ventaja de hacer entrar muy directamente a las personas perceptoras en contacto con una oferta de acciones de apoyo social. Pero corre el riesgo doble de convertir a los servicios sociales en agencias de gestión de prestaciones ( $y$, en especial, de control de sus perceptores y del fraude) y de convertir las rentas mínimas en una prestación discrecional 'de los servicios sociales'. El primer riesgo puede limitar o acabar con la capacidad de los servicios sociales de desarrollar su tarea (ésa sí, suya propia) de acompañamiento y apoyo. El segundo puede degradar la renta mínima a un premio económico discrecional. En el caso de que se considere conveniente mantener en los servicios sociales una función de este tipo, parece imprescindible una clara separación conceptual y, probablemente, una diferenciación funcional en la gestión.

Los servicios sociales tendrían que abordar algunos ajustes en su estructura para desempeñar sus responsabilidades en la acción contra la exclusión. 
Entre ellos, y como ideas para debatir, sugerimos los siguientes:

- Diferenciar y separar las funciones de garantía de ingresos (rentas mínimas, pensiones no contributivas) de las propias de apoyo y acompañamiento social, con independencia de que sea (o no) responsable el mismo departamento de la Administración.

- Definir mejor las responsabilidades de los servicios sociales. El mecanismo más potente es reconocer derechos a los ciudadanos. Cuando (o mientras) eso no sea posible, es necesario empezar a establecer obligaciones claras. Por ejemplo, se podría establecer la obligación de ofrecer alojamiento temporal a quienes no tengan sitio para dormir, o la obligación de ofrecer un determinado proceso de acompañamiento a personas en determinadas situaciones (perceptores de renta mínima o renta activa de inserción, personas que salen de la cárcel).

- Repensar la articulación institucional de los servicios sociales. Hoy día el sector presenta un panorama de gran complejidad, en el que actúan (a veces en el mismo territorio y con el mismo tipo de acciones) varios niveles de administraciones públicas y en el que la colaboración entre la Administración y el tercer sector está marcada por la inestabilidad y la dependencia. Resulta imprescindible una clarificación y simplificación del mapa de actores públicos, y una delimitación más clara de las responsabilidades y obligaciones de cada actor. Igualmente debería repensarse la relación entre la iniciativa social y el sector público, de forma que se valoricen los elementos más positivos del tercer sector (flexibilidad, capacidad de innovación, motivación, proximidad) y se compensen sus limitaciones (selectividad, distribución desigual sobre el territorio, dificultad de garantizar derechos).

\section{Algunas líneas para el desarrollo de la acción de incorporación}

La parte final de este artículo pretende presentar algunas líneas de desarrollo de la acción de incorporación de los servicios sociales que creemos que pueden abrir perspectivas de mejora. Se trata, por tanto de propuestas de desarrollo que deben ser discutidas y que, en parte, nacen de prácticas que se han desarrollado de forma parcial o limitada.

La acción de incorporación social de los servicios sociales debe combinar los ejes de desarrollo personal e integración comunitaria a los que nos hemos referido en el apartado anterior. Estos dos ejes presentan analogías con diferentes formas de acción (la atención individual y los proyectos comunitarios) e incluso con métodos diferenciados de trabajo social (trabajo social individual o de casos, y trabajo social comunitario). Sin embargo, esta diferencia de focos de atención (lo individual y lo colectivo) no debería llevar a una contraposición entre ambas formas de acción, ni a su separación radical. Acompañar los procesos de desarrollo personal pasa por fortalecer los vínculos con otros individuos en su comunidad de las personas marginalizadas, y requiere, por tanto, de acciones de tipo colectivo. Desde el otro lado, una acción de dinamización u organización comunitaria concebida aisladamente puede tener utilidad para el desarrollo general de la comunidad, pero corre el riesgo de dejar fuera a los sectores sociales más excluidos. La acción sobre la que estamos discutiendo aquí, la acción de incorporación de personas con dificultades especiales de integración desarrollada por los servicios sociales, debe saber articular actuaciones más individualizadas y más colectivas sobre los sectores excluidos y la comunidad a la que pertenecen.

\subsection{La importancia de la estrategia comunitaria en el trabajo de incorporación social}

La acción comunitaria de los servicios sociales es vista, en muchos casos, como la tarea pendiente. Aunque las realidades locales son diversas, hay un lamento extendido sobre la ausencia de trabajo comunitario, bien sea por el exceso de demanda de atención individual, o por un escaso convencimiento institucional sobre la utilidad de la acción comunitaria.

En ocasiones, la intervención comunitaria se ha desarrollado como una línea de acción separada de los servicios sociales de atención primaria. Sin embargo, sería probablemente útil concebir el trabajo comunitario como una herramienta de intervención transversal a todos los programas; debería servir para complementar el resto de intervenciones del nivel individual o familiar, servir a sus objetivos de manera articulada. El trabajo comunitario debería permitir:

- Incrementar las conexiones sociales y fortalecer la red social de las personas en dificultad.

- Utilizar las entidades sociales como mecanismo integrador de las personas en dificultad.

- Desarrollar el apoyo mutuo de personas con problemas comunes como recurso complementario de las prestaciones e intervenciones de los profesionales del servicio.

- Incorporar a los sectores socialmente más débiles por problemas de dependencia o exclusión a las organizaciones y entidades ciudadanas, así como las actividades organizadas por ellas.

- Desarrollar la capacidad de interlocución y negociación con los agentes implicados, como mecanismo prioritario de participación en la marcha de los servicios sociales.

- Denunciar y favorecer la participación de los propios colectivos afectados.

Por señalar algunos ejemplos concretos, en el trabajo de incorporación social, el trabajo comunitario permi- 
tiría: la promoción de redes sociales de apoyo para la incorporación de personas en situación de exclusión social; favorecer la sensibilidad social del vecindario, la escuela y las empresas sobre la situación de colectivos con dificultades; mediar en conflictos vecinales; reducir las actitudes discriminatorias; y conseguir la coordinación de las entidades que trabajan con sectores excluidos, mejorando la intervención conjunta y articulada.

Las dificultades existentes para desarrollar esta línea de desarrollo comunitario no son pocas. En primer lugar, es preciso vencer la fuerte presión que la demanda directa y la opinión pública ejercen, en el sentido de que lo importante es atender las situaciones más graves. En segundo lugar, un obstáculo organizativo importante lo constituye la dificultad de combinar las exigencias normativas de la administración pública (sobre todo, las referidas a los horarios y dedicación laboral de los trabajadores, a la posibilidad o no de realizar determinadas acciones) con las del trabajo comunitario.

Conviene recordar que el trabajo comunitario constituye una de las finalidades con las que surge el nivel primario de los servicios sociales, y que justifica su carácter local y descentralizado. Busca favorecer la solución de los problemas antes de que éstos afecten de manera más intensa y requieran de recursos especializados; llevar a cabo acciones para que la propia comunidad prevenga situaciones de drogadicción, hábitos sociales y relaciones familiares, y sea más integradora con los más excluidos, luche contra los prejuicios y en pro de la sensibilización.

Una de las críticas que con más fuerza se han hecho a lo que podemos llamar modelo asistencial de trabajo social en el seno de los servicios sociales es la de tener un mero efecto paliativo de las situaciones de dificultad. Las situaciones de exclusión social son efecto de múltiples causas sociales e individuales, pero sus causas de fondo pertenecen, sobre todo, al campo de las estructuras sociales, es decir, son estructuras sociales, exclusógenas. En la actualidad, la pérdida de la capacidad integradora del trabajo, la reducción de la capacidad protectora de la familia, la inmigración o la propia reducción de la capacidad protectora del Estado se constituyen en causas estructurales que influyen en la generación de situaciones de dificultad. Los factores individuales pueden explicar el grado e intensidad de la dificultad, o el hecho de que afecte con gravedad a unas personas y no a otras, pero la raíz del problema, en muchos casos, es estructural. Es evidente que afrontar estas causas estructurales trasciende la capacidad de acción de los servicios sociales y tiene que ver con políticas más generales. Sin embargo, el tratamiento de estos factores estructurales sí puede incidir en las formas de intervención del trabajo social.

El desarrollo de una estrategia preventiva frente a la exclusión social debería implicar a la comunidad y al conjunto de sus instituciones, empresas, sindicatos y asociaciones. Esta implicación podría articularse en programas de sensibilización, denuncia de situaciones de dificultad, creación de oportunidades de colaboración conjunta destinadas a favorecer la creación de empleo u otras formas de participación social.

Las entidades del sector no lucrativo ocupan un lugar fundamental en la intervención con personas en situación de exclusión en nuestro país. Debido a las limitaciones del sector público para ofrecer respuestas ágiles y especialmente orientadas a los más excluidos, las entidades sociales siguen haciéndose cargo de colectivos que suponen las manifestaciones más extremas de la exclusión social: personas sin hogar, prostitución, personas con problemas de dependencia al alcohol o las drogas. En los últimos años también han asumido buena parte de la atención directa a personas extranjeras con dificultades de integración social.

Las entidades sociales presentan determinadas potencialidades que les han permitido desarrollar recursos de incorporación social diversos y adaptados a la diversidad de los casos atendidos. La acción de las entidades se desarrolla en entornos de carácter flexible, de forma individual o en grupos pequeños (en talleres, aulas o centros); con finalidades distintas a las del planteamiento de una demanda por parte de la persona excluida (formación, búsqueda de empleo, ocupación). La simplicidad de su organización, la falta de dependencias, su cultura y cercanía con los problemas les han permitido llevar a cabo en muchas ocasiones trabajos de incorporación que pueden ser tomados como modelos positivos de intervención. Por el contrario, la acción actual en los servicios públicos tiene lugar en torno a la respuesta a una demanda que debe plantear de forma explícita el usuario, y a la gestión profesional y administrativa de ésta.

En el primer caso, el desarrollo de las actividades formativas o laborales permite el contacto continuado, al menos en tanto que dura dicha actividad, mientras que en la acción pública son más frecuentes los contactos de carácter puntual. En muchos casos, la fuerte demanda de los servicios, su volumen de trabajo, la falta de profesionales y la rigidez de horarios impiden el correcto desarrollo de acciones de acompañamiento.

La discusión sobre si desde instituciones públicas se puede desarrollar directamente un trabajo de acompañamiento y apoyo social en profundidad no es nueva. Ya desde el siglo XIX ha existido una corriente de opinión que sostiene que desde la 'frialdad' del funcionamiento administrativo público no es posible desarrollar una acción 'cálida' de apoyo social. No pretendemos resolver aquí ese debate. Sin duda, una acción profesional próxima de acompañamiento requiere de fórmulas de organización del trabajo adecuadas, que no son las del funcionariado administrativo clásico. Pero éste es un problema que no se produce sólo en la atención social, sino en todos los servicios humanos públicos. 
Sin embargo, sí parece razonable esperar que la administración pública se rija por el criterio de garantizar determinado nivel de atención a todos los ciudadanos que se considere como necesitados de ella. Garantizar el ejercicio de derechos ciudadanos y de obligaciones públicas es algo que el tercer sector ni puede ni debe hacer, y constituye la primera responsabilidad de la administración pública. Dicho de otro modo, la acción de los servicios (sociales) públicos debería regirse mayoritariamente por derechos subjetivos o, en su defecto, por obligaciones, y sólo una pequeña parte, orientarse hacia acciones voluntarias o discrecionales. Las acciones voluntarias y discrecionales son el rasgo distintivo del tercer sector, y en ese tipo de acciones, la Administración sí debería ser subsidiaria.

\subsection{El acompañamiento del desarrollo personal}

La tarea propia y central de los servicios sociales en las políticas de inclusión e incorporación es el trabajo de ‘apoyo social a la incorporación'. Este trabajo social puede definirse como un proceso de 'acompañamiento del desarrollo personal en el contexto de la comunidad'. Concebir la atención de los servicios sociales en estos términos conlleva incorporar varias ideas importantes.

El concepto de desarrollo personal (Casado, 2008) incluye varias ideas en el trabajo por la incorporación. En primer lugar, la idea de proceso o itinerario. Estos términos se vienen utilizando desde hace años en este terreno. Este planteamiento se diferencia de una concepción de la intervención centrada en una situación en un momento del tiempo, caracterizada por determinadas necesidades o carencias que se han de satisfacer con determinados recursos. La idea de proceso o itinerario nos remite a una parte del proceso biográfico de las personas, proceso que puede ser reorientado por éstas bajo los efectos de una serie de intervenciones a lo largo del tiempo. Puesto que remite al proceso o itinerario biográfico de cada individuo, no es lo mismo que una sucesión predefinida y estandarizada de fases o acciones.

En segundo lugar, está la idea de partir de las capacidades de las personas para desarrollarlas y potenciarlas, más que de las carencias para colmarlas. Es evidente que es necesaria una consciencia clara de las limitaciones, las carencias y los obstáculos que afectan a las personas en dificultad. Sin embargo, un enfoque de desarrollo personal pasa por construir a partir de las capacidades, por limitadas que puedan ser en algunos casos. Es así, por otra parte, como se produce el desarrollo personal en la vida de las personas que consideramos como 'no en dificultad' o 'no excluidas'. Esta concepción fundada en el empowerment se diferencia claramente de la que pone el énfasis de la intervención en el llamado 'binomio necesidades-recursos', es decir, en el diagnóstico de las carencias (necesidades) y el acceso a los recursos que las satisfarían.
En tercer lugar, los desarrollos se producen a partir de una situación de partida y evolucionan en cierta dirección, o en diferentes direcciones en diferentes fases: no son el camino que lleva a una meta predefinida. A partir de la situación en la que se encuentra una persona (situación que es resultado provisional de un proceso anterior), su proceso vital puede desarrollarse ‘a mejor' o ‘a peor', y lo hará a lo largo de fases 'mejores' y 'peores'. Acompañar estos procesos e intervenir para favorecer los desarrollos 'positivos', contener cuando se pueda los 'negativos' y aprender de cada etapa significa romper con el esquema de una imagen predefinida de la ‘curación', de la 'integración' lograda y tratar de arrastrar a la persona hacia esa meta.

En cuanto a la idea de acompañamiento, incluye varios elementos:

- La idea de la gestión del caso, del trabajo de caso en su sentido clásico. Ello supone una continuidad en la relación de intervención social y una relación de colaboración y de cierta confianza (véase la proximidad construida en el punto anterior). Requiere igualmente de un nivel importante de autonomía de los intervinientes y las personas atendidas a la hora de determinar el curso de acción y los recursos que se han de emplear (cosa perfectamente compatible con el establecimiento de límites y la rendición de cuentas).

- La idea de participación de las personas en dificultad, que tiene varios sentidos. Por una parte, aceptar el concepto de codiagnóstico, es decir, renunciar a la visión tecnocrática que considera al técnico como el único capacitado para establecer un diagnóstico y establecer que la identificación de la situación debe hacerse de común acuerdo entre profesionales y usuarios. Por otra, la codeterminación del proceso que se ha de desarrollar, es decir, el diseño conjunto de las acciones previstas. Y, en tercer lugar, la coproducción de la atención, tanto en el sentido del establecimiento de tareas y acciones por todas las partes, como la valorización de la aportación que las personas atendidas pueden hacer a su propio proceso, al de otros y a la colectividad.

El concepto de proximidad hace referencia también a varias ideas. En primer lugar, la idea de proximidad 'construida', es decir, de la creación o construcción de vínculos de cercanía y confianza entre personas en dificultad e 'intervinientes' sociales. Ello supone que la relación de acompañamiento del desarrollo personal no puede limitarse al contacto burocrático entre un ciudadano y la administración pública. Supone la necesidad de construir esa relación de confianza tanto en el primer contacto como en el proceso de acompañamiento.

En segundo lugar, la idea de proximidad activa hace referencia a la necesidad de asegurar el acceso de las poblaciones excluidas a los servicios. Dicho acceso no siempre es fácil y no faltan mecanismos de funcio- 
namiento que, de hecho, excluyen a dichas poblaciones (desde requisitos administrativos hasta horarios, pasando por la misma imagen externa de los servicios). La proximidad activa hace referencia a la disposición a 'ir a buscar' a las personas en dificultad allá donde se encuentran. Las prácticas de outreach y de trabajo de calle, por ejemplo, son coherentes con esta idea. La proximidad activa conecta con la idea de proactividad, de anticiparse a la demanda que puede no hacerse explícita.

En tercer lugar, hay que aludir a la idea de proximidad existencial, que se refiere al papel de las propias personas en dificultad en la atención de personas en dificultad. Incorporar a las personas en dificultad, o que han pasado por dificultades, como profesionales o agentes de la atención, así como en el apoyo mutuo, es en ocasiones un modo de facilitar la construcción de la relación de confianza a la que hemos hecho referencia antes, pero también de movilizar saberes y capacidades de intervención diferentes de los de los profesionales. Supone establecer un eslabón entre los profesionales 'externos' a la población atendida y ésta 4 .

\subsection{Diversidad de situaciones y diversidad de respuestas}

La expansión de la acción de los dispositivos de política social parece conducir de forma irremisible a una estandarización y seriación de determinadas acciones. En los ámbitos que se han desarrollado con cierta rapidez, es frecuente el lamento nostálgico por la etapa artesanal y cálida de los inicios, y por la pérdida progresiva de la proximidad y la personalización de la atención. No es infrecuente que mecanismos pensados para la personalización puedan convertirse en rutinas burocráticas. Piénsese en los planes individuales de rehabilitación (PIR) de personas con discapacidad, los contratos de integración de perceptores de la renta mínima de inserción (RMI) o los planes individualizados de atención (PIA) de la LAPAD. Sin embargo, la seriación parece inevitable cuando un determinado tipo de acción afecta a decenas, o cientos de miles, de ciudadanos, y es necesario garantizar una cierta igualdad de trato formal. La única posibilidad de mantener lo positivo y necesario de ambos enfoques es una cierta diferenciación de niveles y de acciones. La LAPAD tiene previsto un mecanismo de este tipo.

Por un lado, una determinación bastante estandarizada del grado y nivel de dependencia conlleva un cierto volumen de recursos asignados a la persona. Por otro, el PIA debería permitir la traducción de ese volumen de recursos en una oferta personalizada y diferenciada de servicios para cada caso. Los contratos de integración en las rentas mínimas tenían una configuración similar sobre el papel: todos los perceptores tenían que tener un contrato, pero el contenido

${ }^{4}$ Véanse los resultados del proyecto de investigación PROXCIT en Barcelona, Montreal y Ámsterdam. (Baillergeau et al., 2010). del contrato se podía establecer con gran libertad, a medida de cada caso. Pero la experiencia nos demuestra que esta diferenciación formal no acaba de funcionar. Seguramente es necesario separar ambas tareas en servicios o equipos diferentes y, sobre todo, establecer un mandato claro a los equipos encargados de la personalización, en el sentido de centrarse en la persona atendida. Más aún, la clave está en dar a la persona atendida una importante capacidad de decisión autónoma sobre el contenido concreto del apoyo, aunque la dimensión del apoyo esté limitada por un mecanismo estandarizado.

Un segundo factor decisivo es el marco de espacio y tiempo que permite desarrollar una acción de acompañamiento. En la intervención social se dan varios tipos de entornos: la consulta en el despacho, la participación en una actividad o un proyecto, la presencia en el hogar, el contacto en la calle, la atención residencial. Cada uno de esos entornos se caracteriza por espacios y tiempos diferentes. Espacios abiertos o cerrados, de parte o neutrales; tiempos breves o más largos, puntuales o frecuentes. El trabajo de acompañamiento puede desarrollarse en una combinación de esos entornos, pero no puede desarrollarse sólo en el tiempo breve y discontinuo, ni en el espacio cerrado e institucional del despacho o la consulta. El trabajo de incorporación social con personas en situación de exclusión requiere de cierta especialización. La naturaleza multidimensional de las situaciones que acumulan dificultades relacionadas con salud mental, dependencia, convivencia, falta de ingresos $u$ otras requieren formas de intervención basadas en la acumulación de saberes y experiencias de trabajo en incorporación social.

Las distintas manifestaciones de la exclusión requieren codiagnósticos e intervenciones individualizadas y adaptadas a cada realidad, que incluyan la aplicación de distintos recursos, junto con fuertes dosis de apoyo personal. Esto hace necesario aplicar metodologías de trabajo social del tipo que se ha venido llamando gestión de casos $^{5}$. En el mundo de la intervención social, se denomina gestión de casos a la metodología de intervención que unifica las responsabilidades sobre cada caso en un mismo profesional o equipo, responsable de la gestión de aquél y de la coordinación de las respuestas diversas que deban ofrecerse. Ello implica una continuidad temporal y una asignación importante de capacidades de decisión (y las correspondientes responsabilidades) al profesional o al equipo encargado de la gestión del caso. Se trata, en definitiva, de crear una relación de referencia entre el caso (persona o familia) y el profesional o equipo que se encarga de su gestión. Significa invertir el esquema que se produce frecuentemente en la atención pública del profesional que atiende cada demanda y la remite a la instancia correspondiente, que es la que decidirá; significa afianzar un modelo en el que el profesional atiende el caso y asume la decisión y la consiguiente responsabilidad.

\footnotetext{
${ }^{5}$ Véase, entre otros, Aguilar Hendrickson et al. (1998).
} 
Precisamente en este nivel de la atención primaria, los profesionales pueden llevar a cabo ese proceso de liderazgo del conjunto de intervenciones y recursos que deben concentrarse en la gestión de casos. Además, el trabajo en el nivel primario permite contar con las potencialidades de incorporación de la propia red social. En los países en los que se inició el desarrollo de la atención primaria, como el Reino Unido, éste se produjo como resultado de un proceso de integración en el nivel local de servicios anteriormente especializados. Es decir, se partía de servicios que, por su especialización, tenían el inconveniente de una visión parcial de los problemas -servicios a menores, discapacitados, enfermos de salud mental-, y se dejaban de lado otras problemáticas relacionadas con la situación de la familia o el aislamiento social. El community care permitía, frente al cuidado institucionalizado, mantener a las personas en su entorno, en su familia, con sus relaciones sociales: aprovechar, en suma, el poder integrador de las redes comunitarias, el asociacionismo, las amistades, el empleo y el ocio. Lo que se pretendía con el cuidado en la comunidad era, precisamente, tratar de manera especializada, pero bajo una visión global, las situaciones. Los servicios comunitarios, además, favorecían la utilización de recursos sociales (familia, asociaciones) en el trabajo especializado, lo que multiplicaba el efecto integrador de los procesos de ayuda. De este modo, en el nivel local se coordinaba la atención a los problemas económicos, de empleo y de salud mental de una única familia.

Sin embargo, en nuestro país la atención primaria ha construido un modelo de atención generalista. El proceso de desinstitucionalización de la atención especializada de salud mental o de menores no se ha integrado en la red de servicios sociales primarios (Aguilar Hendrickson et al., 1998). Precisamente por esta distancia existente en la actualidad entre el trabajo especializado de los servicios de atención a menores y a personas con problemas de salud mental y los servicios comunitarios, es difícil construir procesos de trabajo integral frente a los itinerarios de exclusión social. Es por ello por lo que, en la actualidad, muchas veces se interviene en las mismas situaciones de exclusión desde diversos estamentos (educación, salud mental, atención primaria) de manera fragmentada, sin que desde ninguno de ellos pueda asumirse la responsabilidad global de la intervención.

Es preciso, por tanto, dotar de recursos especializados en la incorporación social al nivel de atención primaria, ya que este nivel presenta importantes potencialidades para la intervención con personas excluidas:

- Éste es el nivel más cercano al terreno y, por ello, en él se pueden llevar a cabo las funciones de detección, acogida, escucha y recogida de las demandas concretas, partiendo de la posición y el momento de cada persona, y detectando demandas no explícitas, por ejemplo.

- Es el nivel en que se pueden realizar diagnósticos exhaustivos que tengan en cuenta todos los aspectos de la situación -familiar, laboral, social-, así como considerar las potencialidades vinculadas a las redes sociales existentes.

- Permite propiciar una primera respuesta a las demandas más acuciantes, favoreciendo el acceso a recursos de garantía de ingresos y otras prestaciones y recursos del propio sistema o del resto. Este acceso debe producirse a través del acompañamiento en el acceso a recursos de empleo, sanidad y vivienda, entre otros.

- Se pueden diseñar de manera negociada los procesos de incorporación social basada en la metodología de trabajo de casos, contando con recursos profesionales propios para la resolución de problemas: educación familiar, motivación, apoyo psicológico, emocional, acompañamiento social. Esto implica la coordinación multidisciplinar entre educadores, psicólogos, técnicos de empleo y trabajadores sociales.

- Se pueden utilizar las potencialidades de la comunidad en cuanto a recursos de empleo, asociaciones, grupos de apoyo, voluntariado y otros.

Es erróneo pensar que todas las personas en situación de exclusión necesitan orientarse principalmente hacia el acceso al mundo laboral. Lo que llamamos de modo un tanto formalista itinerario es el proceso por el que una persona rehace su vida. Sólo cada persona puede rehacer su vida, aunque a veces no pueda hacerlo sin apoyos. El rehacerse de la vida de cada persona es diferente: parte de su historia es única y sigue un camino que es único. Un tratamiento o un proceso formativo puede diseñarse, e incluso estandarizarse. No pasa lo mismo con el proceso de rehacer la propia vida.

A partir de los estudios sobre las condiciones de vida de la población excluida y de la experiencia de intervención, se puede establecer cierta diferenciación de situaciones (Pérez Eransus, 2009):

- Hay personas que, por determinadas circunstancias, se encuentran en desempleo (minorías étnicas, inmigrantes, desempleados de más de 40 años, mujeres solas con cargas familiares), pero que presentan una clara capacidad de trabajar. En algunos casos, tienen cualificación y motivación para el empleo. Podría decirse que se encuentran en la línea de salida para acceder al empleo, pero debido a circunstancias personales, procesos de discriminación, a la alta competitividad del mercado laboral y, en momentos como el actual, a la coyuntura económica, no acceden a él. En muchos casos, llevan a cabo actividades laborales, pero de forma irregular. En estos casos, la estrategia de incorporación puede centrarse en la búsqueda de recursos de activación de carácter formativo y laboral. Sería preciso tener en cuenta, además del seguimiento laboral, un apoyo social continuado que permitiera superar otras problemáticas de la persona, como el acceso a la regularización o a la vivienda. En los casos de personas con cargas 
familiares, pueden ser valiosos los recursos de apoyo, como guarderías, centros de día y similares.

- Hay otras personas que no se encuentran en disposición de incorporarse rápidamente a un empleo, por la falta de experiencia, cualificación o de habilidades y hábitos para el empleo, o por la presencia de problemas personales o familiares. En estos casos, se hacen necesarios recursos prelaborales que favorezcan no sólo la formación ocupacional, sino también la adquisición de hábitos, la estabilidad personal, la mejora de la autoestima o la motivación, entre otras cuestiones; recursos tales como empresas de inserción, centros de empleo o empleo protegido. Con este colectivo, resulta aún más necesario un acompañamiento social paralelo que favorezca la resolución del resto de dificultades.

- Las personas con un nivel elevado de dificultad personal y social poseen una muy difícil empleabilidad. Es el caso de personas sin hogar, toxicómanos, personas con problemas de salud mental. Presentan falta de hábitos para el trabajo, problemas de disponibilidad real, de motivación y, en ocasiones, de marginación. Por esta razón, precisan más preparación personal y profesional previa, así como un acompañamiento más intensivo en el itinerario de incorporación sociolaboral. Los recursos de activación adecuados a estas situaciones (empleo protegido, talleres prelaborales u ocupacionales) deben ser más flexibles, y adaptados a sus ritmos y momentos personales. En estos casos, el eje de la intervención también debe ser el acompañamiento social orientado a mejorar las condiciones de vida de las personas.

- Hay que aceptar también que hay personas cuyas posibilidades reales de empleo son nulas o muy escasas. Sería el caso de personas con severas discapacidades físicas, psíquicas o sociales, en cuyo caso la activación deberá orientarse exclusivamente hacia otros objetivos personales y sociales, y a la mejora de sus condiciones de vida.
De este modo, los procesos de incorporación deben contemplarse como una estrategia que complemente la protección económica, reforzándola y adaptándose a las diversas situaciones analizadas, como hemos visto a través de distintas formulaciones:

- Dispositivos destinados a favorecer la disponibilidad para el trabajo de hogares con cargas familiares no compartidas (recursos de cuidado de menores y mayores).

- Mecanismos de intervención social de carácter integral que permitan superar situaciones de exclusión mediante la coordinación de acciones en distintos ámbitos, como salud, vivienda o acompañamiento social.

- Dispositivos de empleo de carácter ocupacional o social que permitan la utilización del empleo con el fin de 'activar' procesos personales de aquellas personas con problemas de salud mental, problemas físicos o avanzada edad.

- Programas de formación y empleo que favorezcan la cualificación de las personas que sí se encuentran en disponibilidad para incorporarse al mercado laboral normalizado.

El diseño de este último tipo de recursos de activación de carácter más cualificante debe realizarse en colaboración con los servicios de empleo, teniendo en cuenta las características de los usuarios y las necesidades del mercado laboral de cada zona. La situación actual de falta de empleo sin duda debe conllevar un esfuerzo extra por buscar recursos que favorezcan la cualificación a largo plazo, vinculada a salidas laborales específicas, potenciadas por iniciativas de parteneriado público-privado.

En suma, los servicios sociales de atención primaria deberían avanzar en el diseño de un abanico amplio de recursos de incorporación social adaptados a las características y el nivel de empleabilidad de la población excluida. 
AZNAR LÓPEZ, M. (1996): “En torno a la beneficencia y su régimen jurídico”, Civitas. Revista de Derecho Administrativo, № 96, págs. 555-565.

- (1990): “Lugares comunes en acción social sobre la pretendida graciabilidad de la beneficencia", Boletín del CEBS, $\mathrm{n}-23$.

AGUILAR HENDRICKSON, M. (2010): "La huella de la beneficencia pública en los servicios sociales modernos en España", Zerbitzuan, no 48, págs. 9-16 [/http://www.zerbitzuan.net/ documentos/zerbitzuan/La\%2ohuella\%20 de\%2ola\%2obeneficencia.pdf $\rangle]$.

- (2009): "Los servicios sociales: las tribulaciones de un sector emergente", en MORENO FERNÁNDEZ, L. (ed.), Reformas de las políticas de bienestar en España, Madrid, Siglo XXI, págs. 171-206.

AGUILAR HENDRICKSON, M. et al. (1998): "La atención social en la comunidad”, en DEPARTAMENTO DE BIENESTAR SOCIAL, DEPORTE Y JUVENTUD (ed.), Documento base para un plan de atención comunitaria de servicios sociales, Pamplona, Gobierno de Navarra, págs. 15-75 [<http://www. navarra.es/NR/rdonlyres/1EoCEE39-4B1F-4C27BA11-25811A31C598/91938/doc_comp.pdf〉].

BAILLERGEAU, E.; THIROT, M.; y LLOBET ESTANY, M. (2010): "Au contact des invisibles. L'intervention de proximité dans l'espace public", Revue du CREMIS, vol. 3, no 3 , págs. 32-40 [ [rhttp://www. cremis.ca/docs/Vol\%203\%20No\%203\%20 24\%20sept\%202010\%2096\%20dpi.pdf〉].

CARASA SOTO, P. (2007): "Lo privado y lo público en el sistema asistencial: el triángulo IglesiaAyuntamiento-Estado en la beneficencia española", en ABREU, L. (ed.), Asistencia y caridad como estrategias de intervención social: Iglesia, Estado y comunidad (siglos XV-
XX), Bilbao, Universidad del País Vasco, págs. 141-72.

- (2004): “Beneficencia y “cuestión social': una contaminación arcaizante”, Historia Contemporánea, nํ29, págs. 625-670 [khttp:// www.historiacontemporanea.ehu.es/soo21. con/es/contenidos/boletin_revista/00021_ revista_hc29/es_revista/adjuntos/29_04.pdf)].

CÁRITAS ESPAÑOLA (2010): Memoria 2009, Madrid, Cáritas Española [<http://www.caritas.es/memorias. aspx?Id=227〉].

CASADO, D. (2008): “Los servicios sociales: carencias relativas a las situaciones de pobreza y marginación social; y exclusiones y desigualdades de su acción protectora", en ARRIBA GONZÁLEZ DE DURANA, A. (ed.), Políticas y bienes sociales. Procesos de vulnerabilidad y exclusión social, Madrid, FOESSA-Cáritas, págs. 535-609.

- (2002): Reforma política de los servicios sociales, Madrid, CCS.

COLMEIRO, M. (1850): Derecho administrativo español, Madrid; Santiago, Librerías de Don Ángel Calleja.

ESTEBAN DE VEGA, M. (1992): “La asistencia liberal española: beneficencia pública y previsión particular", Historia Social, no 13, págs. 123-138.

GUILLÉN, A. M. (2010): "Defrosting the Spanish Welfare State: The weight of conservative components", en PALIER, B. (ed.), A Long Goodbye to Bismarck? The Politics of Welfare Reform in Continental Europe, Ámsterdam, Amsterdam University Press, págs. 183-206.

KAHN, A. J.; y KAMERMAN, S. B. (1987): Los servicios sociales desde una perspectiva internacional. 
El sexto sistema de protección social. Estudios comparados de diferentes sistemas nacionales de servicio social, Madrid, Consejo General de Colegios Oficiales de Diplomados en Trabajo Social y Asistentes Sociales.

LAPARRA; M.; y PÉREZ ERANSUS, B. (eds.) [2010]: El primer impacto de la crisis en la cohesión social en España. Un análisis provisional a partir de las Encuestas FOESSA, 2007-2009, Madrid, Fundación FOESSA; Cáritas [<http://www. vientosur.info/documentos/Informe\%20 Foessa\%20Caritas.pdf $>$.

PÉREZ ERANSUS, B. (2009): "La activación como estrategia de lucha contra la exclusión social", Documentación Social, no 134, págs. 125-142 [khttp://www.caritas.es/imagesrepository/ CapitulosPublicaciones/484/
Tribuna\%20Abierta\%20Capitulo\%20 02_25_09_2008_12_51_00.pdf〉].

RENES, V. (ed.) (2008): VI Informe sobre exclusión y desarrollo social en España 2008, Madrid, Fundación FOESSA; Madrid, Cáritas Española [rhttp://www.foessa.es/publicaciones_Info. aspx? $\mid$ dd=379>].

RODRÍGUEZ CABRERO, G. (1989): “Orígenes y evolución del Estado de bienestar español en su perspectiva histórica. Una visión general”, Política y Sociedad, no 2, págs. 79-87 ['http://revistas. ucm.es/index.php/POSO/article/view/ POS08989130079A/30671>].

VIDA SORIA, J. (1968): “Asistencia social en el ordenamiento de la Seguridad Social española”, Revista de Trabajo, no 21, págs. 51-73. 